\title{
Safety of Single Vein Anastomosis versus Double Venous Anastomosis in ALT Perforator Flap in Foot and Leg Reconstruction
}

\author{
Mohamed Abdelaal, Ahmed Gaber \\ Plastic Surgery Department, Sohag University Hospital, Sohag University, Sohag, Egypt \\ Email: gaberplastic@yahoo.com
}

How to cite this paper: Abdelaal, M. and Gaber, A. (2019) Safety of Single Vein Anastomosis versus Double Venous Anastomosis in ALT Perforator Flap in Foot and Leg Reconstruction. Modern Plastic Surgery, 9, 65-73.

https://doi.org/10.4236/mps.2019.94009

Received: August 27, 2019

Accepted: October 5, 2019

Published: October 8, 2019

Copyright $\odot 2019$ by author(s) and Scientific Research Publishing Inc. This work is licensed under the Creative Commons Attribution International License (CC BY 4.0).

http://creativecommons.org/licenses/by/4.0/

\section{(c) (i) Open Access}

\begin{abstract}
Introduction: Single or double venous anastomosis in free flap in general and ALT, in particular, is still a matter of debate between micro vascular surgeons. In this study, we will present our experience in single vein anastomosis versus double venous anastomosis in ALT perforator flap used in leg and foot reconstruction as regarding flap outcome, complications, operation time and the need for re-exploration. Patient and Methods: We retrospectively evaluate 60 patients with post traumatic foot and leg defects in the period between January 2014 and January 2018 where free ALT flap was done. The patients were divided into two groups, Group 1 where single vein anastomosis was done and Group 2 where double venous anastomosis was done; we utilize the deep venous system for the anastomosis in all cases. Results: Complete flap survival noticed in 56 cases (93.3\%), defect size ranged from 70 to $200 \mathrm{~cm}$ (mean $126.35 \pm 33.78$ ). There was no difference between the 2 groups as regarding Flap survival, hospital stay, flap complications, donner site morbidity and vascular insufficiency. There is statistically significant difference between both groups as regarding Ischemia time, Operation time, and overall re-exploration rate. Conclusions: Our study suggests that the use of a single venous anastomosis in the venous drainage of anterolateral thigh free flaps is as safe and feasible as the two veins anastomoses.
\end{abstract}

\section{Keywords}

Single Vein, Perforator Flap, Foot Reconstruction

\section{Introduction}

As a result of the evolution of angiosomes, the era of perforator flaps began. Perforator flaps have become increasingly popular in reconstructive microsur- 
gery [1]. The anterolateral thigh (ALT) flap was first reported by Song et al. [2] in 1984 and has become a popular option for soft-tissue reconstruction [3].

Initial experiences with free flap reconstruction carried a failure rate of $40 \%$ to $50 \%$, which has since improved to success rates of $90 \%$ to $99 \%$ [4].

Single or double venous anastomosis in free flap in general and ALT, in particular, is still a matter of debate between micro vascular surgeons.

Many surgeons are doing double venous anastomosis routinely for many reasons especially venous insufficiency or thrombosis which is one of the main causes of flap failure [5].

On the other hand, surgeons doing single vein anastomosis are trying to reduce the operation time and cost which was added by the $2^{\text {nd }}$ anastomosis [6].

In this study, we will present our experience in single vein anastomosis versus double venous anastomosis in ALT perforator flap used in leg and foot reconstruction as regarding flap outcome, complications, operation time and the need for re-exploration.

\section{Patient and Methods}

We retrospectively evaluate 60 patients with post traumatic foot and leg defects in the period between January 2014 and January 2018 where free ALT flap was done.

Preoperatively, full history and examination were taken as regarding age and sex of each patient, cause, size and site of the defect, time since injury to reconstruction, exposure of bone or tendons, and any co-morbid conditions.

The patients were divided into two groups, Group 1 where single vein anastomosis was done and Group 2 where double venous anastomosis was done; we utilize the deep venous system for the anastomosis in all cases.

\section{Inclusion criteria}

Patients with leg and foot defects, any age group, any defect size, exposed bone and tendons, fit for microsurgical operation.

\section{Exclusion criteria}

Un fit patients, superficial wounds, concomitant injuries.

The minimum follow up period was 6 months, and patients were examined for durability of coverage, flap success and the need for re-exploration.

\section{Statistical Analysis}

Data were analyzed using Statistical Package for Social Sciences (SPSS) software program. Qualitative variables were recorded as frequencies and percentages. Quantitative variables were presented as means \pm standard deviation (SD) and compared by student $\mathrm{t}$-test. $\mathrm{P}$-value $<0.05$ will be significant.

\section{Results}

Total number of cases was 60 patients, with post traumatic leg and foot defects. Complete flap survival noticed in 56 cases (93.3\%). Age incidence was ranged 
between 5 and 55 years (mean $23.63 \pm 14.47$ ), sex predilection was 45 males (75\%), defect size ranged from 70 to $200 \mathrm{~cm}$ (mean $126.35 \pm 33.78$ ) and defect site was $19(31.7 \%)$ in leg and $41(69.3 \%)$ in foot.

The patients' demographic data are presented in Table 1 including "number, age, sex, defect size and site, time before reconstruction and follow up time" for each group. We noticed that group 1 was 35 patients while group 2 was 25 patients, age incidence was younger in group 1 than group 2, males were more than females in both groups, defect size was smaller in group 1 than group 2 (p-value $=0.0039)$, defect site was more in foot than leg in both groups. Both groups were equal also in preoperative and follow up period.

Flap survival, ischemia time, operation time, hospital stay, flap complications and donner site morbidity also presented in Table 2 . We notice a statistically significant difference between both groups as regarding operation and ischemia time ( $\mathrm{p}$-value $=0.0001$ ) indicating that cases in group 1 need less operation time than group 2, also the ischemia time was less in group 1 due to the use of one vein in anastomosis. There were no differences between the two groups as regarding the total flap loss rate ( $\mathrm{p}$-value $=0.7268$ ), or other flap complications "infection and partial dehiscence" $(p$-value $=0.9435)$ and donner site morbidity ( $p$-value $=0.9345)$. Also, the hospital stay was nearly the same between both groups.

As regarding the arterial anastomoses (Table 3), in $77.1 \%$ of cases in group 1 , we use posterior tibial artery, while in group 2 we use it with $80 \%$ of cases. In the remaining cases, we use the anterior tibial artery. Venous anastomoses were done with the deep venous system in both groups.

12 cases need re-exploration (20\%) (Table 4), in group 1 there are 7 cases need re-exploration 2 of them were due to arterial spasm which was improved. The other 5 cases were affected by venous thrombosis were thrombectomy, wash with heparin and venous re-anastomosis was done but unfortunately, 2 of them were completely lost. In group 2, 5 cases need re-exploration 1 of them was due to arterial spasm which was improved. The other 4 cases were affected by venous thrombosis were thrombectomy, wash with heparin and venous re-anastomosis

Table 1. Patient demographic data.

\begin{tabular}{|c|c|c|c|}
\hline & Group 1 & Group 2 & P-value \\
\hline Patient number & 35 & 25 & \\
\hline Age (years) & $\begin{array}{c}5 \text { to } 40 \\
\text { Mean } 17.63 \pm 10.7\end{array}$ & $\begin{array}{c}8 \text { to } 55 \\
\text { Mean } 32.04 \pm 15.1\end{array}$ & 0.0001 \\
\hline Sex (percentage) & $\begin{array}{l}\text { Male: } 28(80 \%) \\
\text { Female: } 7(20 \%)\end{array}$ & $\begin{array}{l}\text { Male: } 17(68 \%) \\
\text { Female: } 8(32 \%)\end{array}$ & 0.2940 \\
\hline Defect size $(\mathrm{cm})$ & $\begin{array}{c}70 \text { to } 180 \\
\text { Mean } 115.06 \pm 28.7\end{array}$ & $\begin{array}{c}90 \text { to } 200 \\
\text { Mean } 139.04 \pm 32.7\end{array}$ & 0.0039 \\
\hline Defect site & $\begin{array}{c}25 \text { foot }(71.4 \%) \\
10 \operatorname{leg}(28.6 \%)\end{array}$ & $\begin{array}{c}16 \text { foot }(64 \%) \\
9 \operatorname{leg}(36 \%)\end{array}$ & 0.547 \\
\hline Time before reconstruction & 3 days to 3 weeks & 3 days to 3 weeks & \\
\hline Follow up time & 6 months to 1.5 years & 6 months to 1.5 years & \\
\hline
\end{tabular}


Table 2. Comparing the outcomes for each group.

\begin{tabular}{|c|c|c|c|}
\hline & Group 1 & Group 2 & P-value \\
\hline Ischemia time (minutes) & $\begin{array}{c}30 \text { to } 50 \\
\text { Mean } 40 \pm 7.2\end{array}$ & $\begin{array}{c}45 \text { to } 75 \\
\text { Mean } 59.76 \pm 9.02\end{array}$ & 0.0001 \\
\hline Operation time (minutes) & $\begin{array}{c}180 \text { to } 240 \\
\text { Mean } 208.86 \pm 18.9\end{array}$ & $\begin{array}{c}220 \text { to } 300 \\
\text { Mean } 259.96 \pm 26.8\end{array}$ & 0.0001 \\
\hline Hospital stay (days) & 7 to 14 & 7 to 13 & \\
\hline Total flap loss (percentage) & $2(5.7 \%)$ & $2(8 \%)$ & 0.7268 \\
\hline $\begin{array}{l}\text { Other flap complications } \\
\text { infection, partial dehiscence } \\
\text { and partial loss (percentage) }\end{array}$ & $4(11.4 \%)$ & $3(12 \%)$ & 0.9435 \\
\hline Donner site closure & $\begin{array}{c}12 \text { primary }(34.3 \%) \\
23 \text { with graft }(65.7 \%)\end{array}$ & $\begin{array}{c}10 \text { primary }(40 \%) \\
15 \text { with graft }(60 \%)\end{array}$ & \\
\hline $\begin{array}{l}\text { Donner site morbidity } \\
\text { (percentage) }\end{array}$ & $3(8.6 \%)$ & $2(8 \%)$ & 0.9345 \\
\hline
\end{tabular}

Table 3. Vascular Anastomosis.

\begin{tabular}{cccc}
\hline & Group 1 & Group 2 & P-value \\
\hline \multirow{2}{*}{ Arterial anastomosis } & 27 with posterior tibial a. (77.1\%) & 20 with posterior tibial a. (80\%) & 0.7899 \\
& 8 with anterior tibial (22.9\%) & 5 with anterior tibial (20\%) & 0.7899 \\
Venous anastomosis & single vein anastomosis with & double vein anastomosis & \\
& deep vein & with deep venous system & \\
\hline
\end{tabular}

Table 4. Re-explorations and survival rate.

\begin{tabular}{|c|c|c|c|}
\hline & Group 1 & Group 2 & P-value \\
\hline Overall re-exploration & 7 cases $(20 \%)$ & 5 cases $(20 \%)$ & 0.0001 \\
\hline Arterial spasm cases & 2 arterial spasm (5.7\%): pass & 1 arterial spasm (4\%): pass & 0.7675 \\
\hline Venous thrombosis cases & 5 venous thrombosis (14.3\%) & 4 venous thrombosis $(16 \%)$ & 0.8570 \\
\hline Venous thrombosis & 3 pass $(8.6 \%)$ & 2 pass $(8 \%)$ & 0.9345 \\
\hline outcome & 2 failed $(5.7 \%)$ & 2 failed ( $8 \%)$ & 0.7268 \\
\hline Salvage success rate & $71.4 \%$ & $60 \%$ & 0.3598 \\
\hline Timing of re-exploration & $\begin{array}{c}8 \text { to } 24 \text { hours } \\
\text { Mean } 16.57 \pm 6.08\end{array}$ & $\begin{array}{c}8 \text { to } 36 \text { hours } \\
\text { Mean } 23.2 \pm 10.83\end{array}$ & 0.0037 \\
\hline
\end{tabular}

was done but 2 of them also were completely lost. There was a statistically significant difference in the rate of re-exploration between the two groups ( $\mathrm{p}$-value $=0.0001$ ), indicating that more cases need reoperation in group 1 than group 2 . When analyzing the cause for re-exploration we found that arterial cause was $5.7 \%$ in group 1 and $4 \%$ in group 2 with no difference. The venous cause was $14.3 \%$ in group 1 and $16 \%$ in group 2 also with no statistically significant difference. As we say before, there were no differences between the two groups as regarding the total flap loss rate ( $\mathrm{p}$-value $=0.7268$ ) which were due to venous thrombosis. There was a difference in the timing of the re-exploration between 
the two groups ( $\mathrm{p}$-value $=0.0037$ ) but not reaching the significance indicating that the reoperation was earlier in group 1 than group 2 . Salvage success rate was higher in group 1 than group $271.4 \%$ and $60 \%$ respectively with significant difference.

Case Presentation:

Case (1):

Male patient, 14 years old, affected by motor car accident, have a raw area over the posteromedial aspect of the right foot over tendoachillis. Defect size was $10^{*} \mathrm{~cm}$. K wire fixation was done for fracture dislocation of the ankle joint and soft tissue debridement done also.

Free ALT flap was done. Anastomosis was done end to end with post tibial vessel. The donor site was closed with STG. Late post-operative results were satisfactory (Figure 1 and Figure 2).

Case (2):

Male patient, 10 years old, affected by motor car accident, have a raw area over the dorsum of the right foot. Defect size was $5^{\star} 9 \mathrm{~cm}$. Soft tissue debridement is done also. Free ALT flap was done. Anastomosis was done end to end with post tibial vessel. The donor site was closed primary. Late post-operative results were satisfactory (Figure 3 and Figure 4).

Case (3):

Male patient, 40 years old, affected by motor car accident, have a raw area over the sole of the right foot. Defect size was $7^{\star} 11 \mathrm{~cm}$. Soft tissue debridement is done also. Free ALT flap was done. Anastomosis was done end to end with post tibial vessel. The donor site was closed with STG. Late post-operative results were satisfactory (Figure 5 and Figure 6).

\section{Discussion}

The choice of doing free flap reconstruction in lower limb should be done carefully, depending on multiple factors including age, size and site of the defect, presence or absence of exposed vital structures and patient general condition. Initial experiences with free flap reconstruction carried a failure rate of $40 \%$ to

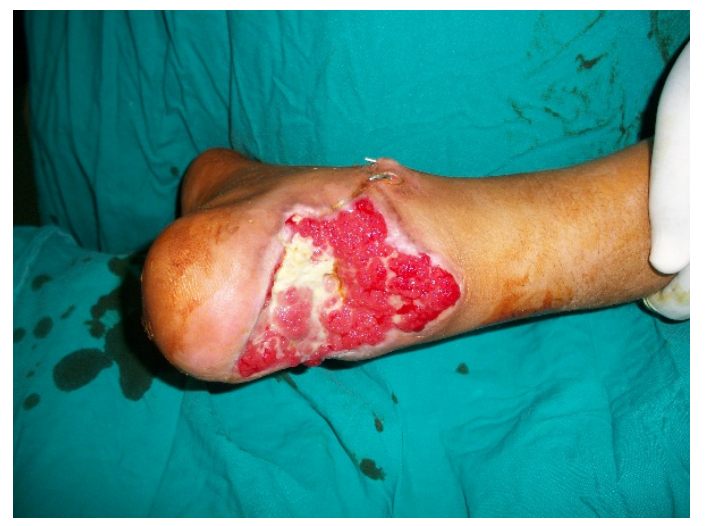

Figure 1. Pre-operative picture of case 1. 


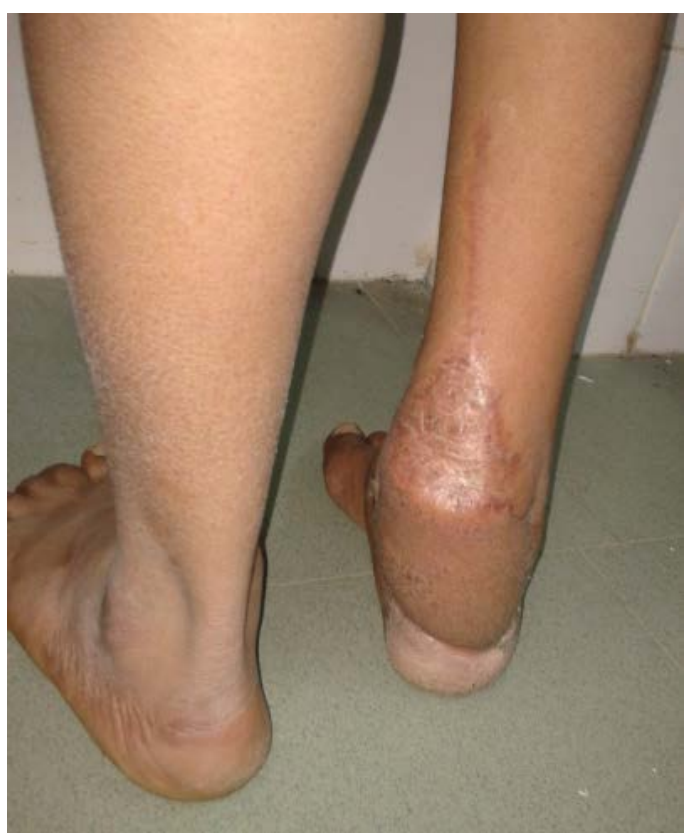

Figure 2. Post-operative picture of case 1.

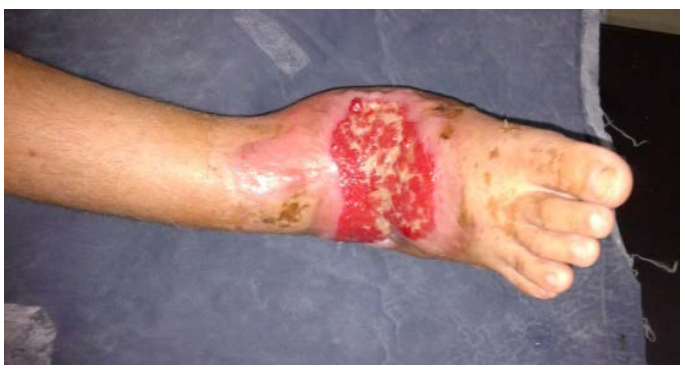

Figure 3. Pre-operative picture of case 2.

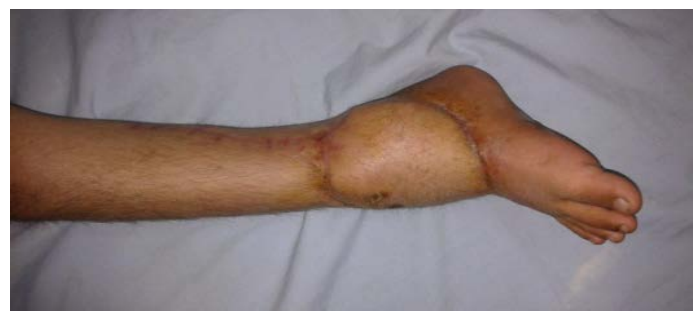

Figure 4. Post-operative picture of case 2.

$50 \%$, which has since improved to success rates of $90 \%$ to $99 \%$ [4]. In our study, we have success rate $93.3 \%$ which is comparable to the literature. Many technical controversies exist regarding the technical details of the microvascular anastomosis in order to prevent the occurrence of thrombosis and in order to optimize outcomes [7]. Anastomosis proximal to the site of injury should be preferred whenever practical [8].

Hanasono et al. in his study present 81 cases of single vein anastomosis and claiming that the blood velocity is high when comparing it with two venous 


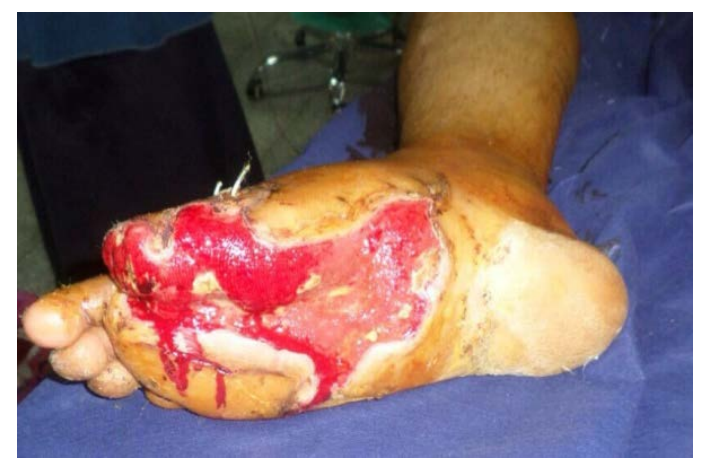

Figure 5. Pre-operative picture of case 3.

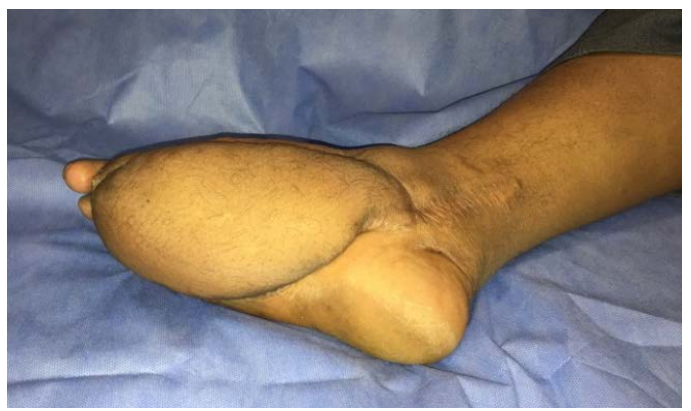

Figure 6. Post-operative picture of case 3.

anastomoses which will reduce the incidence of stasis and subsequently the thrombosis. On the other hand, to enhance venous drainage and especially to provide a rescue venous drainage if one of the venous anastomoses occludes, other authors postulate the use of two or more venous anastomoses [9] [10]. We chose the ALT flap in reconstruction of leg and foot defects for many reasons include donor harvesting with a two-team approach, long length and large caliber of the pedicle, volume variability, minimal donor site morbidity, and the ability to incorporate various tissue components, such as skin, subcutaneous fat, deep fascia, and muscle, in varying proportions as needed [11] [12].

The main complication in free flap surgery remains thrombosis of the vessels, usually venous thrombosis [13] [14]. Vascular complications leading to flap failure can include venous thrombosis, arterial thrombosis, or both. Reasons for flap failure can be divided into technical factors and patient factors. Technical factors, including flap design and surgeon error, are considered common causes of vessel thrombosis [15]. Patient factors, including the known (e.g., age, smoking, obesity, and radiation) and unknown (e.g., unknown coagulopathy and unknown medication effects), can also contribute to vascular compromise [16]. It is important to prevent venous thrombosis in order to achieve a better survival rate. We use the deep venous system for the vein anastomosis in all cases to create a homogenous atmosphere and facilitate the investigation which makes our data more reliable. When analyzing the difference between both groups as regarding venous complications, there was no difference $(p$-value $=0.8570)$ in 
the overall thrombosis rate, salvage rate ( $\mathrm{p}$-value $=0.3598)$ and failure rate (p-value $=0.7268)$.

The initial 72 hours postoperative is the most critical for flap monitoring and stability [17]. In our work, the vascular insufficiency was noticed between 8 to 24 hours postoperatively in group 1 comparing to 8 to 36 hours postoperatively in group 2 with ( $\mathrm{p}$-value $=0.0037$ ) although not reaching the significance but indicating that the vascular insufficiency was noticed earlier in group 1 than group 2 .

The rate of re-exploration between the two groups ( $p$-value $=0.0001$ ) was statistically significant, indicating that more cases need reoperation in group 1 than group 2. When adding $2^{\text {nd }}$ vein for anastomosis it will prolong the operation time that is used to prepare the vein and finish the anastomosis, so it is not surprising that when we analyze the ischemia time and total operation time there was a statistically significant difference between both groups $(p$-value $=0.0001)$ indicating that cases in group 1 need less operation time than group 2 .

\section{Conclusion}

We assume that venous drainage through single vein anastomosis in the ALT free flap with deep venous system provides adequate safety for flap survival. In addition, the single venous anastomosis shortens operative time. Therefore, our study suggests that the use of a single venous anastomosis in the venous drainage of anterolateral thigh free flaps is as safe and feasible as the two veins anastomoses.

\section{Conflicts of Interest}

The authors declare no conflicts of interest regarding the publication of this paper.

\section{References}

[1] Blondeel, P.N., Morris, S.F., Hallock, G.G. and Neligan, P.C. (2006) Perforator Flaps: Anatomy, Technique \& Clinical Applications. Quality Medical Publishing, St. Louis, MO.

[2] Song, Y.G., Chen, G.Z. and Song, Y.L. (1984) The Free Thigh Flap: A New Free Flap Concept Based on the Septocutaneous Artery. Bricd Journal of Plastic Surgery, 37, 149-155. https://doi.org/10.1016/0007-1226(84)90002-X

[3] Wei, F.C., Suominen, S., Cheng, M.H., Celik, N. and Lai, Y.L. (2002) Anterolateral Thigh Flap for Postmastectomy Breast Reconstruction. Plastic and Reconstructive Surgery, 110, 82-88. https://doi.org/10.1097/00006534-200207000-00015

[4] Pattani, K.M., Byrne, P., Boahene, K. and Richmon, J. (2010) What Makes a Good Flap Go Bad? A Critical Analysis of the Literature of Intraoperative Factors Related to Free Flap Failure. The Laryngoscope, 120, 717-723. https://doi.org/10.1002/lary.20825

[5] Coroneos, C.J., Heller, A.M., Voineskos, S.H. and Avram, R. (2015) SIEA versus DIEP Arterial Complications: A Cohort Study. Plastic and Reconstructive Surgery, 135, 802e-807e. https://doi.org/10.1097/PRS.0000000000001150

[6] Han, Z., Li, J., Li, H., Su, M. and Qin, L. (2013) Single versus Dual Venous Anasto- 
moses of the Free Fibula Osteocutaneous Flap in Mandibular Reconstruction: A Retrospective Study. Microsurgery, 33, 652-655. https://doi.org/10.1002/micr.22176

[7] Chen, W.F., Kung, Y.P., Kang, Y.C., Lawrence, W.T. and Tsao, C.K. (2014) An Old Controversy Revisited-One versus Two Venous Anastomoses in Microvascular Head and Neck Reconstruction Using Anterolateral Thigh Flap. Microsurgery, 34, 377-383. https://doi.org/10.1002/micr.22214

[8] Spector, J.A., Levine, S. and Levine, J.P. (2007) Free Tissue Transfer to the Lower Extremity Distal to the Zone of Injury: Indications and Outcomes over a 25-Year Experience. Plastic and Reconstructive Surgery, 120, 952-959. https://doi.org/10.1097/01.prs.0000255175.92201.c7

[9] Ichinose, A., Terashi, H., Nakahara, M., Sugimoto, I., Hashikawa, K., Nomura, T., et al. (2004) Do Multiple Venous Anastomoses Reduce Risk of Thrombosis in Free-Flap Transfer? Efficacy of Dual Anastomoses of Separate Venous Systems. Annals of Plastic Surgery, 52, 61-63. https://doi.org/10.1097/01.sap.0000096425.18223.60

[10] Ross, G.L., Ang, E.S., Lannon, D., Addison, P., Golger, A., Novak, C.B., et al. (2008) Ten-Year Experience of Free Flaps in Head and Neck Surgery. How Necessary Is a Second Venous Anastomosis? Head \& Neck, 30, 1086-1089. https://doi.org/10.1002/hed.20841

[11] Lutz, B.S. and Wei, F.C. (2005) Microsurgical Workhorse Flaps in Head and Neck Reconstruction. Clinics in Plastic Surgery, 32, 421-430. https://doi.org/10.1016/j.cps.2005.02.006

[12] Lee, Y.C., Chiu, H.Y. and Shieh, S.J. (2011) The Clinical Application of Anterolateral Thigh Flap. Plastic Surgery International, 2011, Article ID: 127353. https://doi.org/10.1155/2011/127353

[13] Riot, S., Herlin, C., Mojallal, A., Garrido, I., Bertheuil, N., Filleron, T., et al. (2015) A Systematic Review and Meta-Analysis of Double Venous Anastomosis in Free Flaps. Plastic and Reconstructive Surgery, 136, 1299-12311. https://doi.org/10.1097/PRS.0000000000001791

[14] Tran, N.V., Buchel, E.W. and Convery, P.A. (2007) Microvascular Complications of DIEP Flaps. Plastic and Reconstructive Surgery, 119, 1397-13405. https://doi.org/10.1097/01.prs.0000256045.71765.96

[15] Nahabedian, M.Y., Momen, B. and Manson, P.N. (2004) Factors Associated with Anastomotic Failure after Microvascular Reconstruction of the Breast. Plastic and Reconstructive Surgery, 114, 74-82. https://doi.org/10.1097/01.PRS.0000127798.69644.65

[16] Mirzabeigi, M.N., Wang, T., Kovach, S.J., Taylor, J.A., Serletti, J.M. and Wu, L.C. (2012) Free Flap Take-Back Following Postoperative Microvascular Compromise: Predicting Salvage versus Failure. Plastic and Reconstructive Surgery, 130, 579-589. https://doi.org/10.1097/PRS.0b013e31825dbfb7

[17] Chen, K.T., Mardini, S., Chuang, D.C.C., Lin, C.H., Cheng, M.H., Lin, Y.T., Huang, W.C., Tsao, C.K. and Wei, F.C. (2007) Timing of Presentation of the First Signs of Vascular Compromise Dictates the Salvage Outcome of Free Flap Transfers. Plastic and Reconstructive Surgery, 120, 187-195.

https://doi.org/10.1097/01.prs.0000264077.07779.50 